\title{
Application of Hydrocyclones to Improve Membrane Technologies for Urban Wastewater Treatment
}

\author{
Zhuzbay Kassymbekov ${ }^{1 *}$, Kenzhebek Akmalaiuly', Galimzhan Kassymbekov ${ }^{2}$ \\ 1 Satbayev University, Institute of Architecture and Construction, Department of Engineering Systems and \\ Networks, Almaty, Kazakhstan \\ 2 Kasgidro, Almaty, Kazakhstan \\ * Corresponding author's e-mail: jkk2004@mail.ru.
}

\begin{abstract}
The technologies associated with the use of a membrane bioreactor (MBR) are becoming one of the dynamically developing directions in the wastewater disposal system. However, a certain part of the used design of membrane units are exposed to mechanical contamination, which significantly impairs their performance. This is especially noticeable when working at wastewater treatment plants, where the required degree of preliminary cleaning from solid mechanical particles and suspended solids is not provided. The purpose of the work was to improve the process of post-treatment of urban wastewater and protect the membrane element of the installation from clogging with coarse impurities and wear, with an overestimated concentration of suspended solids. The essence of the improved membrane technology of wastewater treatment consists in the preliminary capture of heavy and suspended particles with a size of more than 0.03 microns in a hydrocyclone, followed by water treatment in a chamber of a membrane bioreactor of modern design. The operating conditions of the membranes were determined by the operating modes and parameters of the bioreactor, in particular, by the degree of formation of colloidal compounds in it, which adversely affect the permeability. The density of the initial water varied within $1.059-1.078 \mathrm{~g} / \mathrm{cm}^{3}$, and the content of solid particles was up to $0.3 \mathrm{~mm}$. The activated sludge was filtered under vacuum on a Buchner funnel through a thin layer of cotton wool and gauze. During the tests, the indicators for capturing suspended solids were $5.0-9.0 \mathrm{mg} / \mathrm{dm}^{3}$, whereas, when working without a hydrocyclone, they were equal to $27-30 \mathrm{mg} / \mathrm{dm}^{3}$. The maximum performance of the hydrocyclone is provided at an inlet pressure of $225-300 \mathrm{kPa}$, and the pressure loss in the hydrocyclone chamber is 7.9-9.0 $\mathrm{kPa}$. It was established that additional preparation of waste water for the post-treatment process using a hydrocyclone increases the cleaning capacity of membrane elements by reducing the load of accumulation of coarse impurities on the membrane surface.
\end{abstract}

Keywords: waste water, post-treatment, membrane technology, hydrocyclone, testing

\section{INTRODUCTION}

Urban wastewater is generated as a result of the economic activities in the housing sector and industrial enterprises, as well as rain and snow [SN RK, 2012; Bogateev, 2010]. They contain dozens of compounds that negatively affect the environment and human health [Karmanov and Polina, 2015]. Wastewater leaks or floods can cause it to enter rivers and other bodies of water [SP RK 4.01-103-2013, 2014].

The pollution of surface wastewater with various products, usually sorbed on suspended particles is typical and most dangerous for water bodies [ITS 10-2019, 2019]. The study of the flows of recycled technological wastewater from metallurgical production, depending on the content of pollutants, shows their relevance [Nosova et al., 2014]. Therefore, before discharging wastewater, it is necessary to conduct special treatment of varying degrees and depths [Fazal et al, 2015].

The most common water purification technology is the mechanical treatment using sand traps and sedimentation tanks, which remove 90 to 95 percent of pollutants [Malovany, 2019]. One of the effective examples of improving such methods is a three-stage wastewater treatment using two paired screens - for preliminary 
treatment, and then filtration through two metal sieves and removal of fine mechanical impurities [Sevostianov et al., 2021]. The principle of operation of the developed technologies for preliminary mechanical water purification based on various methods, including centrifugal separators, is based on the retention of suspended and soluble substances, the size of which exceeds the pore size of the membrane installed in the tank, as well as hydrocyclones [Khurmamatov, 2017; MansurJeffrion, 2010; Senfter, 2017]. Hydrocyclones as a device for cleaning anaerobic digesters of sludge in wastewater treatment plants as well as separating particles and liquids show good results [Bayo et al., 2015; Bhardwaj et al., 2012]. The advantage and effectiveness of the hydrocyclone methods of water purification from mechanical impurities have also been proven in the study in the circulating water supply system and in other areas of their application [Valeev, 2014; Zhurinov et al., 2019; Botantaeva, 2014]. There is some experience in the use of hydrodynamic cavitation to improve the biodegradability index of municipal wastewater that has undergone preliminary mechanical treatment and the use of activated carbon and zero-valent iron [Lebiocka, 2020; Fronczyk, 2020].

Biological treatment plants remove a variety of contaminants from the liquid using special microorganisms [Balandina, 2015]. The rest of microorganisms, products of their activity, other pollutants do not allow water to be discharged in this form into reservoirs. Therefore, the second stage of the process is carried out - post-treatment of waste water, where bioreactors and deep purification filters are used [Rajindar, 2014].

A membrane bioreactor (MBR) is a collection of several porous membranes made of a crystalline polymer with a high molecular weight, intended for the purification of natural and waste waters [Khasanova and Nakipov, 2017].

The increased interest in the technology of membrane reactors in recent years is explained by a significant reduction in the cost of this technology [Mamedova and Guseinova, 2019]. In terms of capital costs, the technology is practically equal to the costs of building a "aeration tank - secondary sedimentation tank - posttreatment facilities" system, while ensuring operational reliability, the possibility of full automation and higher cleaning efficiency.

The use of membrane technology for wastewater treatment prevents the pollution of the existing water bodies and, when reused, can completely eliminate discharges into water bodies [Miklashevsky, 2014]. The presence of such installations reduces the area of treatment facilities during new construction and reconstruction.

It should be noted that most of the standard sizes of the membrane bioreactors used impose strict requirements on the preliminary wastewater treatment. This is due to the fact that the presence of suspended solids and, coarse impurities in the treated water can lead to irreversible pollution and premature failure of membranes [Miklashevsky and Muravyova, 2014].

During filtration, biological and mineral deposits form in the pores and on the surface of the membranes. In order to effectively combat sediments, the modern practice of operating submersible membrane bioreactors involves the use of backwashing with filtrate and reagent solutions [Trunov et al., 2010].

In order to select the measures to prevent salt deposits and reduce the consumption of concentrates, the mechanisms of formation of low-soluble salt deposits in reverse osmosis membrane plants and other suspended particles contained in purified water were studied [Pervov et al., 2019].

When a sediment layer forms on the membrane surface, the process occurs unsteadily, since the sediment layer thickness varies both in terms of the separation time and the length of the membrane module [Fedosov, 2020]. The issues of membrane fouling control and work with flows below critical are considered in the article [Verhuelsdonk et al., 2021]. It notes that early indication can be used as an additional method for detecting contamination.

Overall, this review of the study shows that membrane fouling in the bioreactor continues to limit the widespread use of this technology and increase the operating costs. Thus, the development and study of an improved technological scheme of membrane post-treatment of wastewater, which protects the unit membrane from clogging by impurities and wear, is relevant.

\section{DESCRIPTION OF THE INSTALLATION AND METHOD OF STUDY}

An improved technological scheme for wastewater treatment using a membrane bioreactor (Figure 1, innovative patent of the Republic of Kazakhstan No. 21444) includes bioreactor 1; sewage pump 2 equipped with a hydrocyclone 3 . 
The pump is connected to the automatic control panel by means of a cable 4 . In order to supply purified water from the hydrocyclone to the reservoir 6 , a drain line 5 is provided, at the end of which a hydromonitor nozzle 15 is installed. With the help of the latter, the compacted activated sludge is recirculated on the lower part of the membrane module 7 .

Compressed air is supplied to the membrane module by compressor 8 , and the suction of purified water from the module is done using a vacuum pump 9. The volume of water supplied to the consumer is recorded using a flow meter 10 , and the pressure in the network is exemplary pressure gauges 12 . There is a valve on the suction branch of the hydrocyclone 13. The membrane module is suspended on a rope 14 . The water level in the tank is controlled by the action of the float 16, which, when changing the position, gives the command to turn the module on and off as well as pumps 2 and 9 through the automatic control panel.

Initial experiments were carried out in order to study the flow-pressure characteristics of a hydrocyclone, since it must correspond to the technological parameters of a membrane bioreactor, and then experiments were carried out to establish the quality indicators for wastewater treatment using a hydrocyclone.

Joint tests of the hydrocyclone unit and the membrane module "Mikrodin" were carried out in summer at the site of the wastewater treatment plant in Nur - Sultan as part of the wastewater treatment process line (Figure 2). The prototype of the installation was manufactured according to the technological scheme (Fig. 1).
During testing, the operating conditions of membranes in biomembrane processes were determined by the modes and parameters of the bioreactor, which are associated with the degree of formation of colloidal compounds in it, which negatively affect the permeability and resistance of the membranes [Mamedova, 2019].

In order to provide water supply to the hydrocyclone from the aeration tank, the test bench was equipped with an ALKO Imp. Sewage pump. ALKO GERATE GmbH with a capacity of 1.51 / s, a head of $34 \mathrm{~m}$ and a power of $12.5 \mathrm{~kW}$.

The structural dimensions of the main elements of the hydrocyclone varied within the following limits: the diameter of the inlet and outlet nozzles was $25-50 \mathrm{~mm}$, the diameter of the sand hole was $12.5-25 \mathrm{~mm}$, and the diameter of the cylindrical part remained constant, which was $200 \mathrm{~mm}$.

The concentration of suspended solids in the aerotanks ranged from 20-25 g/l, and sometimes up to $100-118 \mathrm{~g} / \mathrm{l}$, when, as a technological regulation for a membrane submersible module, the content of suspended solids is allowed up to $12 \mathrm{~g} / \mathrm{l}$.

This provision required a decrease in the contamination of the treated waste water before entering the membrane and trapping the mechanical impurities larger than 0.04 microns. The latter is associated with the conditions for matching the particle diameters with the pore sizes of the membranes.

At the concentrations of activated sludge greater than $8000 \mathrm{mg} / \mathrm{l}$, the intensity of sedimentation on the membranes increases, the pressure through the membrane increases rapidly, and the efficiency of the process decreases. In the case when the concentration of activated sludge

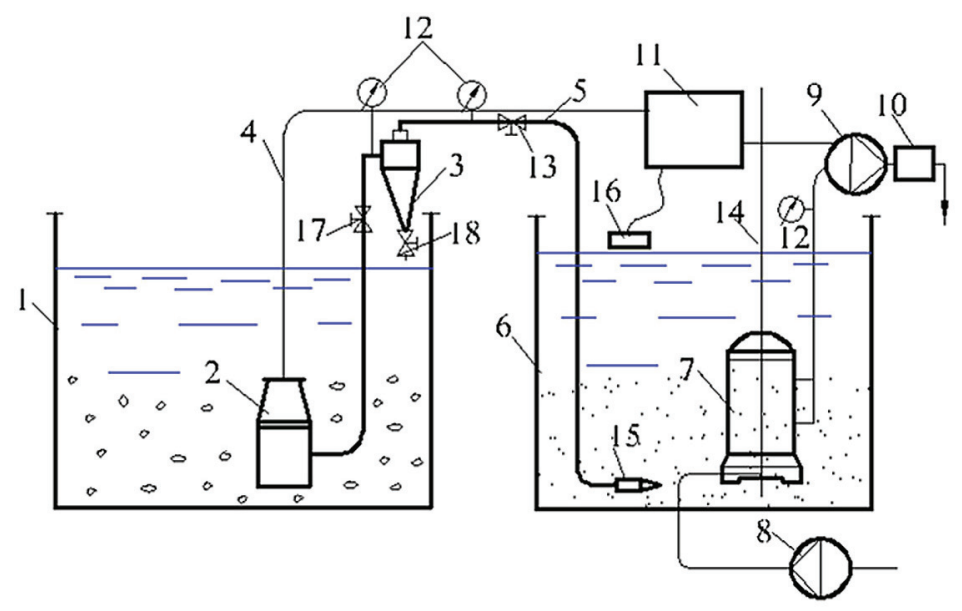

Figure 1. Wastewater treatment scheme according to the developed technological scheme with a hydrocyclone (designations in the text) 


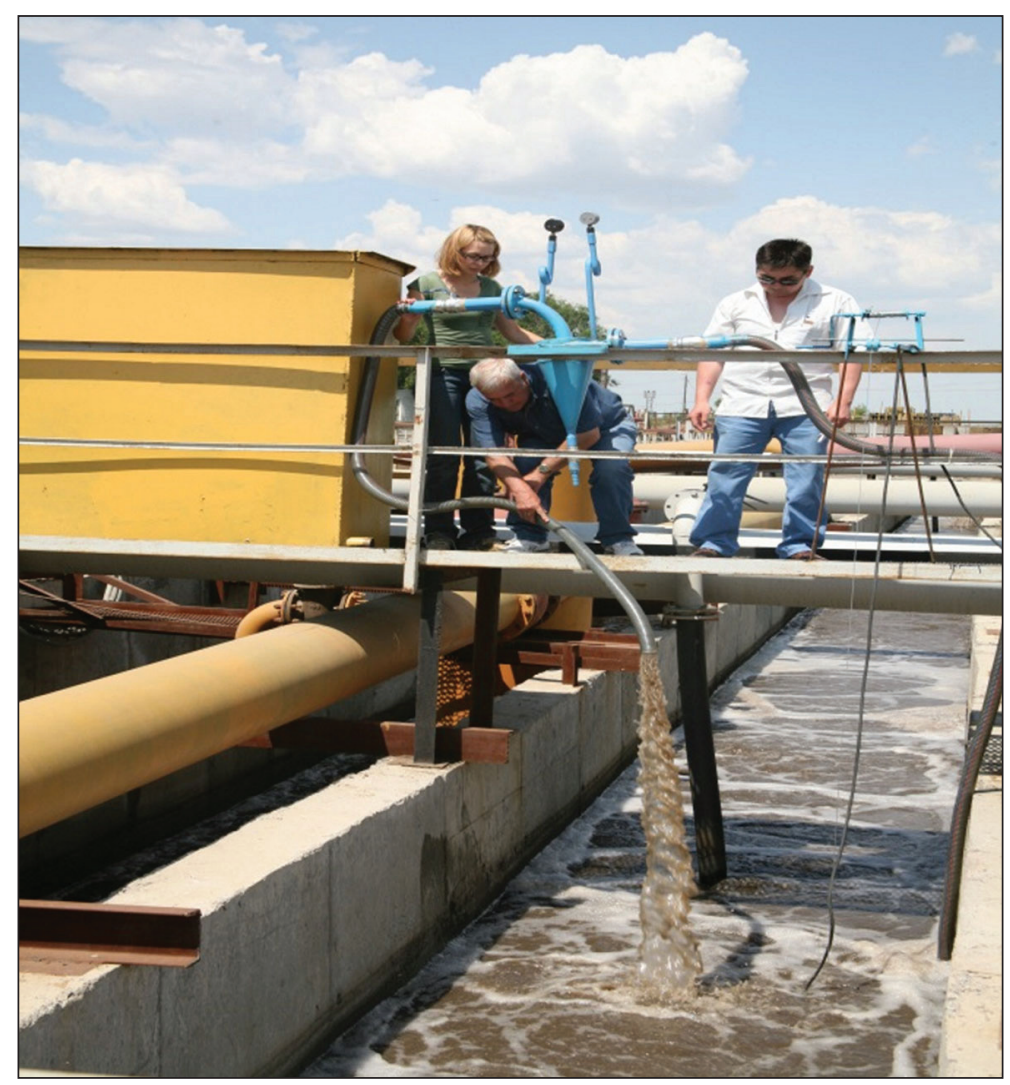

Figure 2. General view of the hydrocyclone-membrane unit

decreases below $3000 \mathrm{mg} / \mathrm{L}$, the option of increasing the concentration by thickening it through the sand holes of the hydrocyclone was used (SN RK, 2012). The temperature range was $-15-35^{\circ} \mathrm{C}$.

This situation was also observed when using the basic "Mikrodin-Nadir" module (Germany) for the additional biological treatment of waste water in the wastewater treatment facilities of Nur-Sultan according to the project of the Department of Energy and Utilities of the city (Dossaev, 2017).

The choice of filtering material was carried out according to the retention capacity, process selectivity (97\%). During the test period, the density of water varied from 1.059 to $1.078 \mathrm{~g} / \mathrm{cm}^{3}$. The maximum diameter of solid particles reached $0.3 \mathrm{~mm}$. In case of a violation of the stabilization supply of prepared water to the membrane module, with the required output parameters, the installation mode was corrected with the help of valves and by changing the position of the submersible pump.

The processing of experimental data when testing the hydrocyclone and membrane module was carried out using the least squares method. The deviation in the processing results was expressed as a normal Gaussian curve. [ITS 10-2019, 2019].
The separation accuracy was determined by the formula (for draining):

$$
E_{p m}=(d 25-d 75) / 2
$$

where: $E_{p m}-$ average probable deviation, $\mathrm{mm}$; $d 25, d 75$ - average size of the class, 25 and $75 \%$ of which, respectively, is extracted into the drain, $\mathrm{mm}$.

\section{RESULTS AND DISCUSSION}

The experimental data obtained show that at a steady-state operating mode of the hydrocyclone chamber, when the pressure at the inlet Pen changes within the range of $150.0-300.0 \mathrm{kPa}$, the flow rate through the drainage pipe $Q_{p}$ increases from $0.940 \mathrm{l} / \mathrm{s}$ to $1.167 \mathrm{l} / \mathrm{s}$, and through the sandbox $Q_{d}-$ up to $4.42 \mathrm{l} / \mathrm{s}$. (Figure 3).

The maximum performance of the hydrocyclone is provided at an inlet pressure of 225-300 kPa, when the valve on the pressure line is open to its full cross-section. The pressure loss in the hydrocyclone chamber $d P=7.9-9.0 \mathrm{kPa}$.

These indicators were obtained when the ratio of the diameters of the sandy $d_{p}$ and drainage 
$d_{d}$ wells $\frac{d_{p}}{d_{d}}=0.5-1.0$. With a decrease in the unloading coefficients of the hydrocyclone chamber to $0.3-0.4$, the flow rate Qp decreases. However, the qualitative change to function $Q_{d}, Q_{p}=f\left(P_{e n}\right)$ remains.

Comparison of pressure losses in the hydrocyclone shows that in the operating mode under pressure, their change occurs in direct proportion to the pressure, and also depends on the geometric parameters.

The pressure loss increases along with the sand hole diameter.The established separation characteristics of the process are represented in Figure 4.

These data show that with an increase in the content of solid particles at the inlet $(\mathrm{Ca})$ of the hydrocyclone from 86 to $91 \%$ (classes $<0.045 \mathrm{~mm}$ ), the size of the boundary separation $(\delta)$ increases from 0.02 to $0.07 \mathrm{~mm}$, and the average deviation - from $0.04 \mathrm{~mm}$.

The experimental results show that, depending on the operating conditions and the composition of the raw material, the size of the boundary separation varies from 0.04 to $0.24 \mathrm{~mm}$. It turned out that the limiting factor in improving the quality of treated water for hydrocyclones is the fact that a significant part of the water polluting particles, which are complex "solid activated sludge", have a density close to that of the waste. water. In this regard, they are not always ejected onto the inner peripheral surface of the hydrocyclone even at high tangential velocities.

As expected, high relative thickening $(\operatorname{Cotn}=$ 5.10-5.84) of the slurry with the least water loss through the sand well was achieved when the hydrocyclone was operating to form a "sand block".

In order to maintain the specified rational regime for thickening, it is necessary to ensure the optimal value of the specific load on the sand hole $\left(\mathrm{qp}=1.35-1.45 \mathrm{t} / \mathrm{h}\right.$ per $1 \mathrm{~cm}^{2}$ ) by regulating the cross-section of the outlet hole using a throttling device, mainly automatic.

As the obtained dependences of the specific productivity of the membrane module for purified water $\left(\mathrm{q}, 1 / \mathrm{m}^{2}, \mathrm{~h}\right)$ on pressure $(\mathrm{P}, \mathrm{bar})$ show, when using a hydrocyclone, an increase in throughput is observed up to $19.61 / \mathrm{m}^{3}$. In turn, when working without a hydrocyclone, it is $14.2-14.51 / \mathrm{m}^{3} . \mathrm{h}$ (Figure 5).

The biological treatment parameters obtained in the established mode of the Mikrodin-Nadir membrane unit are shown in Table 1.

$\mathrm{T}$ was found that after an increase in pressure over 225-230 bar, the permeate output stabilizes and tends to decrease. With a uniform supply of water treated in a hydro cyclone to the reservoir, the output of water from the module fluctuates within the range of $16.0-18.01 / \mathrm{m}^{3} . h$, which provides a rational regime for additional treatment.

It turned out that with a decrease in the depth of wastewater treatment in purified water, the concentration of the extracted substances increases. This is explained by the fact that during biochemical purification, various substances are consumed by bacteria in different ways; the readily oxidized substances are removed faster, while maintaining the required duration of the waste water stay in the aeration tank.

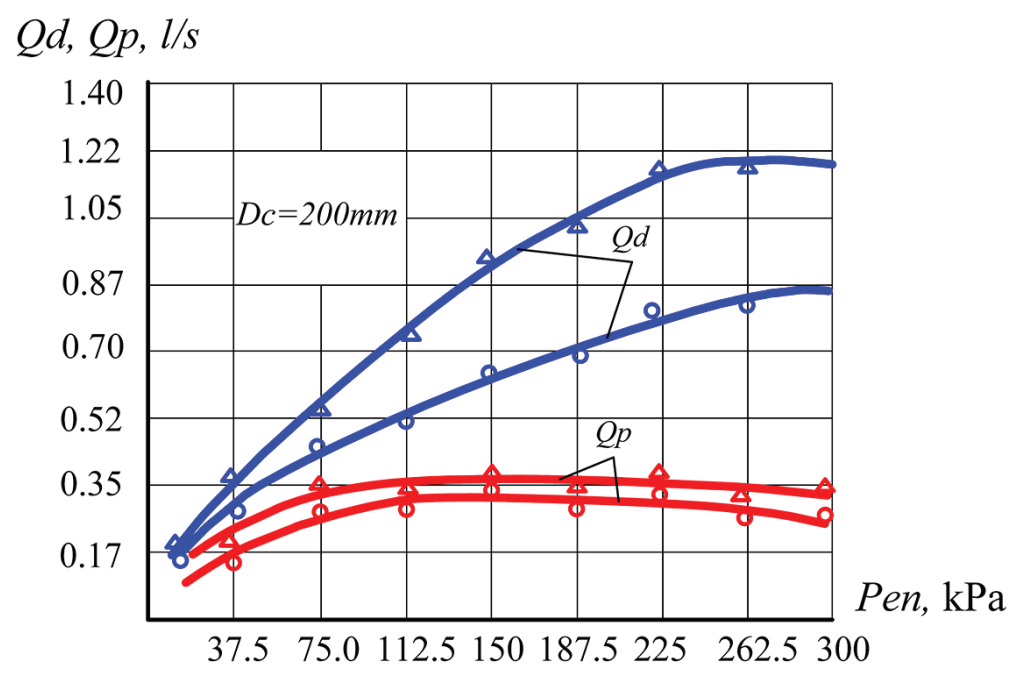

Figure 3. Characteristics of a hydrocyclone for a membrane unit 


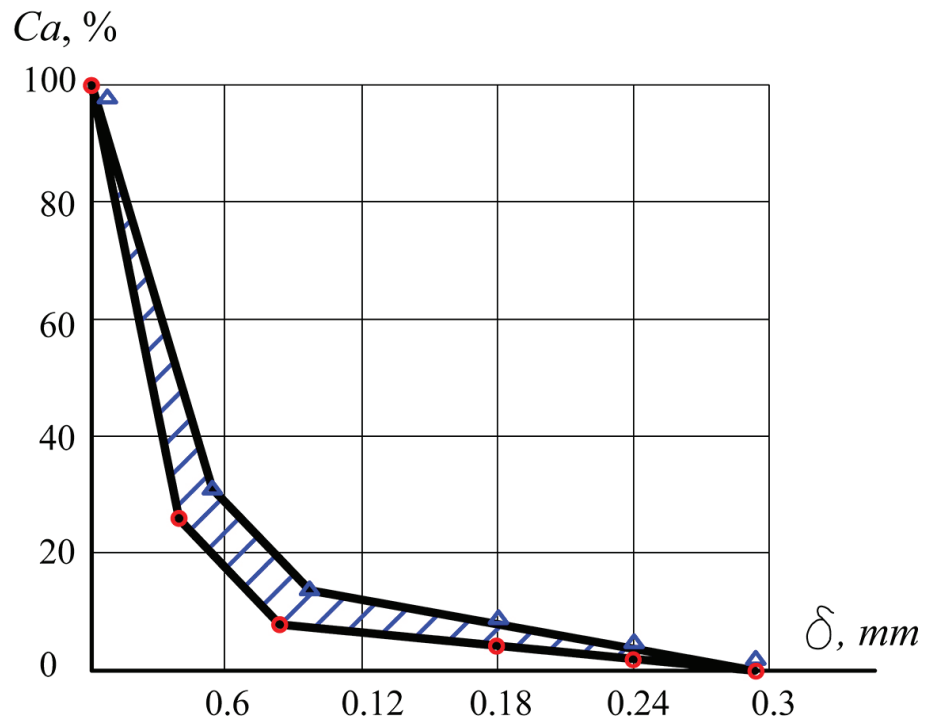

Figure 4. Granulometric composition of the sucked-in sand during testing

$q, 1 / \mathrm{m}^{3 *} \mathrm{~h}$

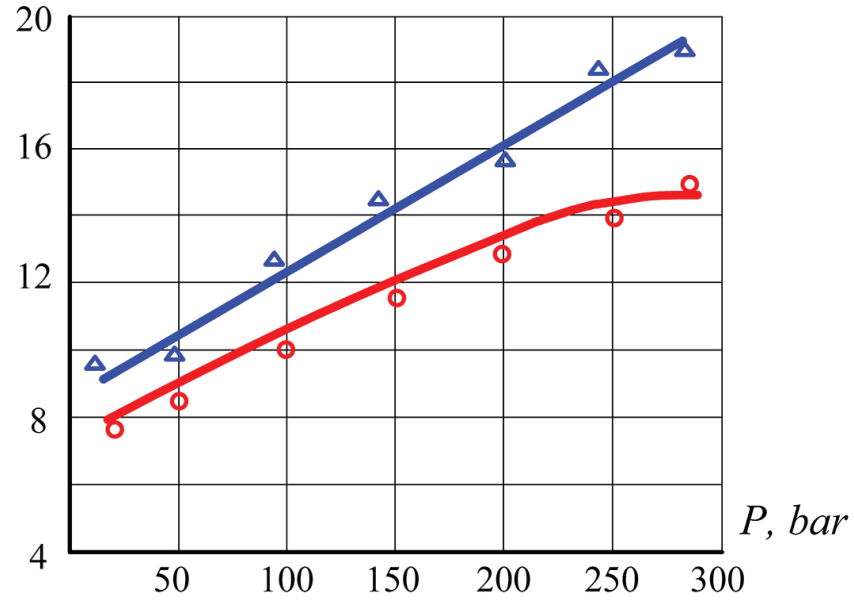

Figure 5. Graphs of permeate yield versus pressure with and without hydrocyclone, $\Delta$ - with a hydrocyclone; o - without a hydrocyclone

Table 1. Indicators of wastewater treatment and post-treatment during production testing of the unit with and without a hydrocyclone

\begin{tabular}{|c|c|c|c|c|c|}
\hline Component name & Unit & $\begin{array}{c}\text { Indicators of } \\
\text { source water in the } \\
\text { aeration tank }\end{array}$ & $\begin{array}{l}\text { Cleaning the } \\
\text { installation } \\
\text { «Mikrodin Nadir» }\end{array}$ & $\begin{array}{c}\text { Cleaning } \\
\text { together with a } \\
\text { hydrocyclone }\end{array}$ & $\begin{array}{c}\text { Maximum } \\
\text { allowable } \\
\text { concentration }\end{array}$ \\
\hline Suspended substances & $\mathrm{mg} / \mathrm{l}$ & $1150-1340$ & $\begin{array}{c}4.1 \\
22.3 \\
35.0 \\
24.1\end{array}$ & $\begin{array}{l}1.20 \\
1.15 \\
0.95 \\
2.65 \\
2.11\end{array}$ & $\begin{array}{c}\text { No more than } \\
0.75 \text { of the } \\
\text { background }\end{array}$ \\
\hline Dry residue & $\mathrm{mg} / \mathrm{l}$ & $1130-2100$ & $\begin{array}{l}1056 \\
1101 \\
1000\end{array}$ & $\begin{array}{c}1000 \\
1003 \\
998\end{array}$ & 1000 \\
\hline Nitrates (by NO3) & $\mathrm{mg} / \mathrm{l}$ & $0,44-13,60$ & $\begin{array}{l}3.5 \\
4.3 \\
7.1 \\
5.8\end{array}$ & $\begin{array}{l}2.90 \\
3.89 \\
6.50 \\
5.23\end{array}$ & 45 \\
\hline Nitrite (by NO2) & $\mathrm{mg} / \mathrm{l}$ & $0,085-0,160$ & $\begin{array}{l}0.022 \\
0.053 \\
0.071 \\
0.078\end{array}$ & $\begin{array}{l}0.018 \\
0.050 \\
0.069 \\
0.076\end{array}$ & 3,3 \\
\hline Mechanical impurities & $\mathrm{mg} / \mathrm{l}$ & $1900-3100$ & $0.402-0.242$ & $\begin{array}{l}0.102 \\
0.142 \\
\end{array}$ & - \\
\hline
\end{tabular}


As expected, the concentration of impurities exceeded up to $30.0 \mathrm{mg} / \mathrm{l}$. leads to a decrease in the throughput of the membrane to $48.0 \mathrm{l} / \mathrm{h}$. A change in pressure in the range of 100-250 bar has a positive effect on the selectivity of the membrane separation, but due to the seal of the membrane, the latter becomes less permeable to impurities. Providing a flow-through separation mode helps to remove or reduce the accumulation of soluble matter on the membrane surface and maintains the production process at the required level.

A linear increase in selectivity at low inlet pressures and its stability at low concentrations of impurities after the hydro cyclone are characterized in almost all operating modes of. It was found that with an increase in permeability, the selectivity decreases from 98.5 to $96.3 \%$.

\section{CONCLUSIONS}

The use of a hydrocyclone in the post-treatment of wastewater using membrane technology helps to protect the membrane against clogging with coarse impurities and wear, especially when the concentration of suspended solids is too high. Due to this, an increase in the throughput of the unit for treated water, as well as an increase in selectivity at low inlet pressures and its stability at low concentrations of impurities after cleaning in a hydrocyclone are achieved. Providing a flow-through separation mode helps to remove or reduce the accumulation of soluble matter on the membrane surface and maintain the production process at the required level.

When using a hydrocyclone, the activity of microorganisms in the bioreactor does not deteriorate, which allows maintaining the intensive process of biological treatment.

The considered variant of the membrane technology is expedient to be used mainly at local water treatment facilities with a productivity in the range of $70.0-85.0 \mathrm{l} / \mathrm{h}$.

\section{REFERENCES}

1. Balandina A.G., Khangildin R.I., Martyasheva V.A., Shundeeva E.V.2015. Hardware for the treatment of difficult-to-oxidize wastewater. Bashkir Chemical Journal, 22, 101-108(in Russian).

2. Bayo J., Lapez-Castellanos J., Martanez-Garcaa R., Alcolea A., Lardan C.2015. Hydrocyclone as a cleaning device for anaerobic sludge digesters in a wastewater treatment plant, Journal of Cleaner Production, 87, 550-557.

3. Bhardwaj P., Bagdi P., \& Sen A.K.2012. Microfluidic device based on a micro-hydrocyclone for particle-liquid separation. Lab on a Chip, 11(23).

4. Bogateev I.A., Polyakov A.M. 2010. Design and construction of small domestic wastewater treatment plants using membrane bioreactor technology (MBR): Int. Forum “Clean Water'2010” / JSC "Mosvodokanalproekt” .- Moscow(in Russian).

5. Botantaeva B.S.,Kassymbekov Zh.K., Ni N.P. 2014. Testing of the water-pipe centrifugal vent valvepressure damper in laboratory conditions. Water and Ecology, 2(58),39-44(in Russian).

6. Fazal S., Zhang B., Zhong Z., Gao L., Chen X. 2015. Industrial wastewater treatment by using MBR (Membrane Bioreactor). Review study. Jour- nal of Environmental Protection, 6, 584-598.

7. Fedosov S.V., Osadchiy Yu.P., Markelov A.V. 2020. Modeling of the ultrafiltration process taking into account the formation of sediment on the membrane surface. Membranes and membrane technologies. Publisher: MAIK "Science / Interperiodica" (Moscow), 177-189.

8. Fronczyk J. 2020. Properties of Reactive Materials for Application in Runoff Water Treatment Systems. J. Ecol. Eng.21(8),185-197.

9. ITS 10-2019. 2019. Wastewater treatment using centralized drainage systems for settlements, urban districts. Best Available Technology Information Technology Handbook, 416.

10. Karmanov A.P., Polina I.N.2015. Wastewater treatment technology. Tutorial, 207(in Russian).

11. Khasanova Z.R., Nakipov A.R.2017. Exact Science Magazine Waste water treatment using MBR technology (membrane bioreactor), 67-71(in Russian).

12. Khurmamatov A.M. 2017. Influence of the size of solid particles of mechanical impurities on the efficiency of cleaning a hydrocyclone. Institute of General and Inorganic Chemistry of the Academy of Sciences of RUz, 6, 47-50(in Russian).

13. Lebiocka M. 2020.Application of Hydrodynamic Cavitation to Improve the Biodegradability of $\mathrm{Mu}-$ nicipal Wastewater.J. Ecol. Eng.21(6),155-160.

14. Malovanyy M.,Moroz J.,Hnatush S., Maslovska O., Ihor P.I., Volodymyr N.V., Sereda A. 2019. Perspective Technologies of the Treatment of the Wastewaters with High Content of Organic Pollutants and Ammoniacal Nitrogen. J. Ecol. Eng., 20(2), 8-14.

15. Mansour-Geoffrion M., Dold P., Lamarre D., Gadbois, A.2010. Characterizing hydrocyclone performance for grit removal from wastewater treatment activated sludge plants. Minerals Engineering, 23(4), 359-364. 
16. Mamedova F.M., Guseinova M.A. 2019. Use of Membrane Bioreactor in Wastewater Treatment. Modern Science Magazine, 6(1), 198-204.

17. MiklashevskyN.V.,MuravyovaT.S.2014.Ultrafiltration and reverse osmosis. Purification of natural and waste waters. Water resources and water use, 8(127).

18. Miklashevsky N.V. 2014. Wastewater treatment using MBR technology. Plumbing, eating and air conditioning, 12, 34-41.

19. Nosova O. V., Karmanovskaya N. V., Galishevskaya V. V. 2018. Study of water flows of technological water circulation and wastewater metallurgical production in relation to the content of pollutants. Periodico Tche Guimica, 15(30), 550-555.

20. Pervov A.G., Andrianov A.P., Golovesov V.A., Danilycheva M.N. 2019. Study of the mechanism of formation of crystalline deposits in membrane devices and the role of inhibitors to prevent this process. Membranes and membrane technologies. Publisher: MAIK "Science / Interperiodika” (Moscow), 430-444 (in Russian)

21. Rajindar S. 2014. Membrane Technologies and Engineering for Water Treatment: Application, System Design and Operation, 2nd Edition. - Kindle Edition, 452.

22. Sevostianov I., Ivanchuk Y.,Polishchuk J., Lutsyk V., Dobrovolska K., Smailova S., Wójcik W., Kalizhanova A. 2021. Development of the Scheme of the Installation for Mechanical Wastewater Treatment.J. Ecol. Eng.; 22(1), 20-28.

23. Senfter T., Pillei M., Berger M., Bockreis A., Rauch W. and Kraxner M. 2017. Influence of the Viscosity on the Velocity Propagation in Axial Direction in a Rietema Hydrocyclone, AIChE - American Institute of Chemical Engineers - Annual Meeting, Minneapolis USA.

24. SN RK 4.01-03-2011.2012. Wastewater disposal. External networks and facilities (with changes and additions as of 07.11.2019) (in Russian)

25. SPRK 4.01-103-2013. 2014. External networks and water supply and sewerage facilities (with changes and additions as of 25.12.2017) (in Russian).

26. Valeev S.I., Bulkin V.A. 2013. The use of hydrocyclones for wastewater treatment in the circulating water supply system. Bulletin of Kazan Technological University, 16(15), 294-296.

27. Verhuelsdonk M, Glas K.and Parlar H. 2021.LongTerm Operation of a Pilot-Scale

28. Membrane Bioreactor Treating Brewery Wastewater: Relaxation as a Method for Detection of Membrane Fouling. Journal of Environ. Engineering, 147(4).

29. Zhurinov M., Kassymbekov Zh., Kassymbekov G. Zh. 2019. Mastering and development hydropower in Kazakhstan. The National Academy of Sciences of the Republic of Kazakhstan, Series of Geology and Technical Sciences, 3(435), 219-224. 